\title{
Role of glycogen synthase kinase-3 beta in the inflammatory response caused by bacterial pathogens
}

\author{
Ricarda Cortés-Vieyra ${ }^{1}$, Alejandro Bravo-Patiño ${ }^{1}$, Juan J Valdez-Alarcón ${ }^{1}$, Marcos Cajero Juárez ${ }^{1}$, B Brett Finlay ${ }^{2}$ and
} Víctor M Baizabal-Aguirre ${ }^{1,3^{*}}$

\begin{abstract}
Glycogen synthase kinase $3 \beta$ (GSK3 $\beta$ ) plays a fundamental role during the inflammatory response induced by bacteria. Depending on the pathogen and its virulence factors, the type of cell and probably the context in which the interaction between host cells and bacteria takes place, GSK3 $\beta$ may promote or inhibit inflammation. The goal of this review is to discuss recent findings on the role of the inhibition or activation of GSK3 $\beta$ and its modulation of the inflammatory signaling in monocytes/macrophages and epithelial cells at the transcriptional level, mainly through the regulation of nuclear factor-kappaB (NF-KB) activity. Also included is a brief overview on the importance of GSK3 in non-inflammatory processes during bacterial infection.
\end{abstract}

Keywords: GSK3 $\beta$, NF-KB, Inflammation, Virulence factors, Bacterial infection

\section{Background}

Glycogen synthase kinase 3 (GSK3), in its two isoforms GSK3 $\alpha$ and GSK3 $\beta$, is a multifunctional Ser/Thr kinase found in eukaryotes [1]. This enzyme phosphorylates and regulates the function of more than 50 substrates [2] and it is a point of convergence for numerous cellsignaling pathways involved in various essential cellular functions, such as glycogen metabolism, cell cycle control, apoptosis, embryonic development, cell differentiation, cell motility, microtubule function, cell adhesion and inflammation [1-3]. The view of GSK3 $\beta$ has changed from an obscure metabolic kinase to an enzyme that profoundly regulates many components of the innate and adaptive immune systems. The broad array of immune actions affected by GSK3 $\beta$ is partly attributable to the remarkable number of crucial transcription factors that it regulates [4]. The main objective of this review is to show

\footnotetext{
* Correspondence: baizabal@umich.mx

${ }^{1}$ Centro Multidisciplinario de Estudios en Biotecnología, Facultad de Medicina Veterinaria y Zootecnia, Universidad Michoacana de San Nicolás de Hidalgo, Morelia, Michoacán, Mexico

${ }^{3}$ Centro Multidisciplinario de Estudios en Biotecnología, Facultad de Medicina Veterinaria y Zootecnia, Universidad Michoacana de San Nicolás de Hidalgo, Km. 9.5 s/n Carretera Morelia-Zinapécuaro, La Palma, Tarímbaro, C.P. 58893, Morelia, Michoacán, Mexico

Full list of author information is available at the end of the article
}

the importance of GSK3 $\beta$ in innate immunity against bacterial infections through regulation of the inflammatory response induced by virulence factors.

\section{General properties of GSK3}

There are two major mammalian GSK3 protein isoforms

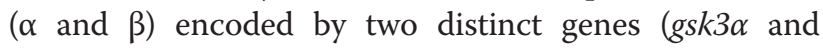
gsk3 $\beta$ ) [5] that are highly homologous within their kinase domains (approximately $98 \%$ of identity), but with only $36 \%$ identity in the last $76 \mathrm{C}$-terminal amino acid residues [5]. Both isoforms are structurally similar but not functionally identical because ablation of the GSK3 $\beta$ isoform in mice resulted in embryonic lethality via hepatocyte apoptosis. The inability of GSK3 $\alpha$ to rescue the GSK3 $\beta$-null mice indicates that the degenerative liver phenotype arises specifically from the loss of the beta isoform. Although severe hepatocyte cell death could be due to $\beta$-catenin inhibition of NF-kB, increased amount of $\beta$-catenin in GSK3 $\beta$ $(-/-)$ cells was not found [6]. Physical inhibitory interaction between $\beta$-catenin and NF- $\mathrm{kB}$ is likely a mechanism for tumor size progression mediated by $\beta$-catenin [7]. Alternatively, GSK3 $\alpha$ knockout mice are viable but display enhanced glucose and insulin sensitivity accompanied by reduced fat mass [8]. Mechanisms that regulate GSK3 activity are not yet fully understood. The precise control 
appears to be achieved by a combination of intracellular localization, phosphorylation, and interactions with GSK3 binding proteins [2]. In this regard, GSK3 has been traditionally considered a cytosolic protein; however, it is also present in the nucleus and mitochondria, where it is highly active compared with the cytosolic form [9].

The crystal structure of GSK3 $\beta$ has provided insight into both the regulation of its activation and its inhibition by phosphorylation [1]. GSK3 is activated by phosphorylation of Tyr216 (GSK3 $\beta$ ) or Tyr279 (GSK3 $\alpha$ ) and it is inactivated by phosphorylation of Ser9 (GSK3 $\beta$ ) or Ser21 (GSK3 $\alpha$ ). Several protein kinases can phosphorylate Ser9 and Ser21, including the protein kinase $\mathrm{B}(\mathrm{PKB} / \mathrm{Akt})$, protein kinase $\mathrm{A}$ (PKA), protein kinase $\mathrm{C}$ (PKC) and ribosomal protein 6 kinase (S6K) $[2,10]$. The inactivation of GSK3 $\beta$ by phosphorylation, carried out mainly by Akt, may result in the activation of transcription factors such as AP-1 (Jun family), cAMP-response element binding protein (CREB), signal-transducer and activator of transcription 1-3 (STAT1-3), $\beta$-catenin, and nuclear factor-kappaB (NF-кB) in response to bacterial infections [2,3] (Figure 1).

$\mathrm{NF}-\mathrm{kB}$ plays a critical role in the inflammatory response and it has been traditionally used as an indicator of proinflammatory gene expression in cells exposed to bacterial infections. When an inflammatory stimulus induces the phosphorylation of IкB by the I $\kappa B$ kinase (IKK) complex, the NF- $\mathrm{kB}$ heterodimer ( $\mathrm{p} 50 / \mathrm{p} 65)$ is free to translocate to the nucleus and activates pro-inflammatory gene expression. GSK3 $\beta$ is important for the modulation of NF- $\mathrm{kB}$ because p65 (RelA), p105 (NF-kB1) and B-cell lymphoma 3-encoded protein (BCL-3) (a transcriptional co-activator of NF- $\mathrm{kB}$ p50 homodimer) are phosphorylated in vitro by this kinase $[12,14]$. GSK3 $\beta$ promotes a rapid NF- $\mathrm{kB}$ activation wave by targeting the TNF $\alpha$-/p65-dependent pathway and limiting NF- $\mathrm{KB}$ activation in BCL-3-dependent pathways [10] stabilizing and preventing p105 degradation in unstimulated cells [15]. However, GSK3 $\beta$ also catalyzes the phosphorylation of p105, which in turn activates the phosphorylation and degradation of IKK upon tumor necrosis factor alpha (TNF- $\alpha$ ) treatment [15].Therefore, in basal or stimulated cells GSK3 $\beta$ plays a double function upon p105 [15]. Moreover, GSK3 plays distinct roles in the regulation of NF- $\mathrm{kB}$, depending on the physiological state of the cell. This enzyme promotes survival and stimulates the activity of NF- $\mathrm{KB}$ in cells treated with TNF- $\alpha$ or in tumor cells in which the NF- $\mathrm{BB}$ pathway is constitutively active. In contrast, in quiescent cells GSK3 suppresses the expression of growth factor-inducible genes and induces apoptosis or cell cycle arrest by inhibiting both the IKKphosphorylation of IкB $\alpha$ and the nuclear translocation of p50 and p65 subunits of NF-kB [16].

In view of the contrasting effects that GSK3 plays as a functional regulator of the cell activity, the following sections of this review discuss our current knowledge about the importance of GSK3 $\beta$ as a regulator of the inflammatory process triggered by bacterial virulence factors. Also, in the last section a brief overview on the non-inflammatory phenomena induced by bacteria is presented, which are correlated with the activity of GSK3.

\section{The inflammatory response}

Inflammation is the body's primary response to infection or injury and is critical for both innate and adaptive immunity. Upon infection, a variety of cytokines, chemokines, lipid mediators and bioactive amines are secreted by resident tissue cells, primarily macrophages, dendritic cells, natural killer cells, and mast cells. These factors immediately trigger a local increase of blood flow, capillary permeability and recruitment of additional circulating leukocytes via extravasation. This acute inflammatory response is characterized by the arrival of neutrophils, monocytes that differentiate into macrophages at the site of inflammation, and dendritic cells. This process is complex and involves many different signaling pathways. Most of our knowledge about pro-inflammatory signaling pathways has been obtained from studying the molecules of signaling pathways that are initiated by the activation of tumor necrosis factor receptor (TNFR), interleukin 1 receptor (IL1R), and Toll-like receptors (TLRs) [17]. Activation of TLRs by a variety of pathogen associated molecular patterns (PAMPs) or virulence factors can induce the expression of inflammatory cytokines and other molecules that help to eliminate pathogens and instruct pathogen-specific adaptive immune responses [18]. Cytokines, primarily derived from mononuclear phagocytic cells and other antigen-presenting cells (APCs), are effective in promoting the cellular infiltrate and tissue damage characteristic of inflammation. Monocytes are potently triggered to produce cytokines through the stimulation of pattern recognition receptors (PRRs). The pro-inflammatory cytokines predominantly produced by monocytes include TNF, IL-1, IL-6, CXCL8 (IL-8) and other members of the chemokine family IL-12, IL-15, IL18, IL-23 and IL-27 [19].

During inflammation, leukocytes amplify the response but excessive or prolonged inflammation may cause damage to the host. In normal circumstances, the immune system has several mechanisms to resolve the inflammatory responses that require the termination of pro-inflammatory signaling pathways and clearance of inflammatory cells, allowing the restoration of normal tissue function. Failure of these mechanisms may lead to chronic inflammation and disease [20]. In addition to cytokines that stimulate cytotoxic, cellular, humoral, and allergic inflammation, several cytokines have predominantly anti-inflammatory effects, including IL-1Ra, TGF- $\beta$, IL-10 and IL-35 [21]. Recently, a number of reports have documented that GSK3 $\beta$ activity is crucial to regulate the 


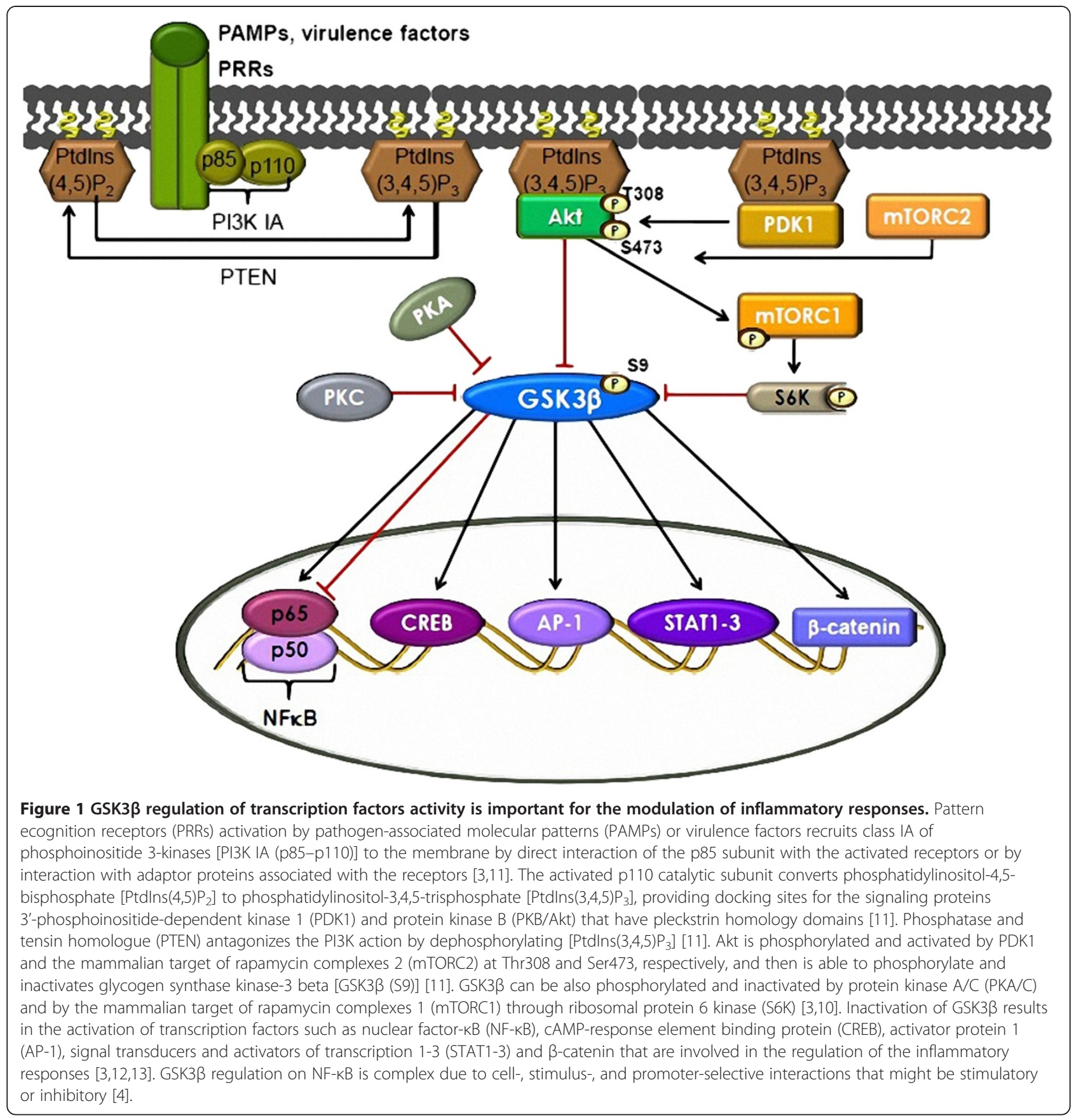

inflammatory response either promoting or inhibiting the process through the expression of pro- or antiinflammatory cytokines.

\section{Inhibition of inflammation by inhibition of the GSK3 $\beta$ activity}

Several studies have demonstrated that inflammation is regulated by the TLR-dependent activation of PI3K-Akt signaling pathway [3,22-26]. A breakthrough paper by Martin et al. [27] established that the PI3K-Aktdependent inhibition of GSK3 $\beta$ activity in human monocytes, stimulated with lipopolysaccharide (LPS), differentially affected the nature and magnitude of the inflammatory response through the activation of TLR2. This in turn resulted in the production of the antiinflammatory cytokine IL-10, while production of proinflammatory cytokines IL-1 $\beta$, IL-6, TNF, IL-12 and IFN- $\alpha$ fell substantially. Inhibition of GSK3 $\beta$ negatively modulated the inflammatory response because it differentially affected the nuclear activity of NF- $\mathrm{kB}$ (p65 subunit) and CREB through the interaction with the coactivator CREB-binding protein (CBP) [27]. In a recent 
study carried out in monocytes stimulated with LPS, it was established that the mammalian target of rapamycin complex 1 (mTORC1) regulates the activity of GSK3 $\beta$ through the activation of $\mathrm{S} 6 \mathrm{~K}$, affecting the inflammatory response by inactivation of GSK3 $\beta$. Furthermore, the inhibition of GSK3 $\beta$ by mTORC1 affected the association of NF- $\mathrm{kB}$ (p65 subunit) and CBP [10].

GSK3 $\beta$ activity negatively regulated the level of the anti-inflammatory cytokine IL-1Ra while concurrently increased the levels of IL1 $\beta$ in LPS-stimulated human monocytes. The PI3K-Akt-dependent inhibition of GSK3 increased the production of IL-1Ra due to its ability to modulate the activity of extracellular-signal-regulated kinase $1 / 2(E R K 1 / 2)$ [28]. These results and the fact that IL-1Ra counteracts the inflammatory properties of IL- $1 \beta$ [29] showed that in LPS-stimulated human monocytes the inhibition of GSK3 $\beta$ increases the production of anti-inflammatory cytokines and reduces the expression of pro-inflammatory cytokines, confirming the model proposed by Martin et al. [27], in which GSK3 $\beta$ in its active form acts as a positive regulator of inflammation.

In a study with Mycobacterium bovis BCG as a Mycobacterium model, it was demonstrated that GSK3 $\beta$ inhibition through the PI3K-Akt signaling increased the production of IL-10 in primary human blood monocytes (PHBM) [30]. Among the cytokines induced by BCG in PHBM, IL-10 was the key factor suppressing the production of interferon- $\gamma$ (IFN- $\gamma$ ) in response to mycobacterial infection. Moreover, IL-10 expression induced by BCG was able to suppress the IFN- $\gamma$-dependent expression of HLA-DR, an inducible MHC class II molecule whose primary function is to present peptide antigens to the immune system. These findings suggest a significant role for GSK3 $\beta$ in guarding against mycobacterial evasion of host immunity, via IL-10 expression.

The PI3K-Akt signaling pathway activation following the nucleotide oligomerization domain 2 (Nod2) recognition of the agonist muramyldipeptide (MDP), a structure from peptidoglycan (PGN), negatively regulates the NF- $\mathrm{B}$ pathway and interleukin (IL)-8 expression through inactivation of GSK3 $\beta$. These results suggest that the PI3K-Akt-GSK3 $\beta$ pathway may be involved in the resolution of inflammatory responses induced by Nod2 activation [31].

Lipoteichoic acid (LTA) is a membrane-bound cell wall component of Gram-positive bacteria and is believed to be the equivalent of LPS of Gram-negative bacteria. Treatment of human gingival fibroblasts (HGFs) with LTA activated Akt which in turn inactivated GSK-3 and promoted the accumulation of $\beta$-catenin, resulting in an increase of connexin43 expression [32]. Given that the interaction of $\beta$-catenin with $N F-\kappa B$ leads to a decrease of the NF- $\mathrm{kB}$ ability to bind DNA and induce gene expression $[7,33]$, it is likely that the accumulation of $\beta$-catenin in LTA-stimulated HGFs causes a negative regulation of the $\mathrm{NF}-\mathrm{kB}$ activity and that this gives rise to a decrease of the pro-inflammatory cytokines production [32]. It is also likely that GSK-3 $\beta$ inactivation might be able to modulate the transcription of specific pro-inflammatory genes containing a T-cell factor/ lymphoid enhancer-binding factor (TCF/LEF) binding site in their promoter. In this regard, it was recently demonstrated that $\beta$-catenin induces pro- and antiinflammatory responses simultaneously as a result of differential gene expression carried out by Wnt/ $\beta$-catenin signaling through a TCF/LEF consensus sequence and NF- $\mathrm{kB}$ modulation in the context of liver cancerrelated inflammation [34].

Innate immunity and inflammatory responses play central roles in the pathophysiology of myocardial ischaemia/reperfusion (I/R) injury and heart failure. In this context, it was observed that PGN administration induced cardio protection in hearts of mice subjected to ischaemia, followed by reperfusion. Activation of the PI3K-Akt-GSK3 $\beta$ signaling pathway and reduction of the NF- $\mathrm{kB}$ nuclear translocation were the main factors responsible for the protection [35]. Although one may assume that reduction of NF- $\mathrm{kB}$ nuclear translocation decreased swelling, this waits further demonstration.

\section{Inhibition of inflammation by activation of GSK3 $\beta$}

In neonatal mouse cardiomyocytes and heart tissue culture, LPS increased the activity of GSK3 $\beta$ and its inhibition with chemical and genetic inhibitors enhanced LPS-induced p65 phosphorylation at the residue Ser536 and increased TNF $\alpha$ expression [36]. Furthermore, in line with GSK3 $\beta$ dephosphorylation at Ser9, Akt phosphorylation at Thr308 was reduced in LPS-treated cardiomyocytes and chemical inhibition of PI3K-Akt attenuated LPS-induced TNF $\alpha$ expression. These results suggest that PI3K-Akt-dependent inactivation of GSK3 $\beta$ plays an important function in LPS-induced TNF- $\alpha$ expression.

\section{Induction of inflammation by inhibition of GSK3 $\beta$ activity}

The production of pro- and anti-inflammatory cytokines by activation of TLR2 and TLR4 in macrophages is dependent upon signaling events initiated by the adaptor molecules TIR-domain-containing adaptor protein (TIRAP) and myeloid differentiation primary response gene 88 (MyD88) [13]. In contrast, inactivation of GSK3 $\beta$ by phosphorylation at Ser9 in macrophages occurred in the absence of MyD88 [32]. In this case, GSK3 $\beta$ activity was a critical component of the regulatory mechanism that controlled the levels of IFN $\beta$ in TLR4-stimulated cells both in vitro and in vivo [37]. In particular, it was shown that inhibition of GSK3 $\beta$ activity augmented the levels of IFN $\beta$ in LPS-stimulated 
macrophages whereas the ectopic expression of a constitutively active GSK3 $\beta$ mutant caused a reduction of the IFN $\beta$ production. Interestingly, inhibition of GSK3 $\beta$ controlled the cellular levels of the transcription factor c-Jun that turned out to be necessary for GSK3mediated IFN $\beta$ production. The conclusion from these results is that GSK3 $\beta$ acts as a critical regulatory kinase that modulated the MyD88-independent synthesis of IFN $\beta$ and of MyD88-dependent production of pro- and anti-inflammatory cytokines, demonstrating the existence of a cross-talk signaling network between these two pathways with GSK3 $\beta$ as a central kinase [37].

The intracellular infection of monocytes and macrophages with Burkholderia cenocepacia, a Gram-negative bacterium associated with exacerbated inflammation [38], caused the activation of PI3K-Akt signaling that in turn inactivated GSK3 $\beta$ and enhanced NF- $\mathrm{kB}$ activity, with the subsequent production of pro-inflammatory cytokines such as, TNF $\alpha$, IL-6 and IL-8. Interestingly, NF- $\mathrm{KB}$ activation did not require the activation of IKK or NF- $\mathrm{kB}$ p 65 phosphorylation, indicating that the inactivation of GSK3 $\beta$ was the major mechanism by which PI3K-Akt modulated the NF- $\mathrm{kB}$ activity without affecting B. cenocepacia uptake or survival [38].

\section{Induction of inflammation by activation of GSK3 $\beta$}

A model in which IFN- $\gamma$ specifically inhibits TLR2dependent production of IL-10 in macrophages by increasing the activity of GSK $3 \alpha / \beta$, and decreasing the expression and activity of CREB and AP-1 proteins has been established [39]. Moreover, at the same time of IL10 suppression, IFN- $\gamma$ induced the expression of TNF $\alpha$. In this study GSK3 and CREB/AP-1 were key players in the signaling activated by the IFN- $\gamma$ receptor and TLR2.

Microglial inflammation caused by pathogenic $S$. aureus occurred through modulation of GSK3 $\beta$ activity that positively regulated the NF- $\mathrm{KB}$-dependent production of TNF $\alpha$ and nitric oxide (NO) [35]. GSK3 $\beta$ negatively regulated IL-10 production, and this inhibition affected the protection against heat-inactivated $S$. aureus-induced microglial inflammation [40]. These authors showed that TNF $\alpha$ acted upstream of NO production and that inhibition of GSK3 $\beta$ blocked heat-inactivated $S$. aureusinduced NF- $\mathrm{kB}$ p65 nuclear translocation.

In the study of the mechanisms by which GSK3 $\beta$ positively modulates the inflammatory response in LPSstimulated microglia, Wang et al. (2010) [41] showed that inhibition of GSK3 $\beta$ activity by selective pharmacological inhibitors or its gene silencing by small interfering RNA suppressed TNFa production by blocking the NF- $\mathrm{KB}$ p65 transactivation activity through deacetylation of p65 at Lys310. In addition, these authors also demonstrated that inhibition of GSK3 $\beta$ blocked mixed lineage kinase 3 (MLK3) activity leading to a reduction of TNF $\alpha$ expression.

The role of GSK3 $\beta$ in modulating the $\beta$-catenin response in colon inflammation caused by pathogenic Salmonella Typhimurium was examined by using a streptomycinpretreated mouse model [33]. $S$. Typhimurium induced an increase in $\beta$-catenin phosphorylation by augmenting GSK3 $\beta$ activity, reducing total $\beta$-catenin expression and compromising the physical cytoplasmic interaction between $\beta$-catenin and NF- $\kappa B$. I $\mathrm{kB} \alpha$, the well-established negative regulator of NF- $\mathrm{KB}$, was degraded in a similar manner as $\beta$-catenin after Salmonella infection. Following

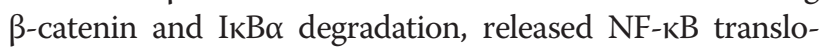
cated to the nucleus and stimulated the production of the pro-inflammatory cytokines IL-6 and IL-8 [33]. The results of this study suggest a novel role for $\beta$-catenin as a negative regulator of NF-kB activity in vivo. Altogether, these data suggest that inhibition of GSK3 $\beta$ as well as $\beta$-catenin and I $\mathrm{B} \alpha$ stabilization provides important control points in the inflammatory cascade of colonic epithelial cells.

The mechanisms by which IFN- $\gamma$ synergizes with LPS to induce iNOS/NO (important inductors in inflammatory cytokine production) biosynthesis in macrophages involve GSK3 $\beta$-dependent inhibition of CREB activity and IL-10 expression [42]. IFN- $\gamma$ co-administration with LPS was also used to study the inflammatory responses modulated by GSK3 in mouse primary glia cultures [43]. In this case, active GSK3 decreased the expression of chemokine CXCL2/ MIP-2 and increased the expression of pro-inflammatory molecules CXCL1/KC, IL-12p40, CCL9/MIP-1 $\gamma$, CCL2/ MCP-1, P-Selectin and CCL5/RANTES. However and most prominently, active GSK3 promoted IL-6 expression due to the cooperative actions of STAT3 and GSK3 during neuro-inflammation. The production of IL-6 by glia was largely blocked by inhibiting the activity of STAT3 or GSK3 $\beta$, revealing the strong dependence of IL- 6 production on these signaling molecules [43]. These data reflect the cell's ability to hyper-response to TLR-induced IFN- $\gamma$ production regulated by GSK3 $\beta$, resulting in a synergism of the inflammatory response.

The opposing functions of GSK3 $\beta$ in the inflammatory response described in the text are summarized in Table 1.

\section{GSK3 regulation of non-inflammatory cellular processes activated by bacterial components}

The Helicobacter pylori virulence factor VacA is one of the most important toxins that contributes to the pathogenesis and severity of gastric injury in infected humans [44]. Although it is still controversial whether cross-talk exists between the PI3K-Akt and Wnt pathways [45], the work of Nakayama et al. [46] showed that VacA induced two effects on $\beta$-catenin in gastric epithelial AZ-521 cells. The first one was the activation and nuclear 
Table 1 GSK3 $\beta$ modulation of the inflammatory response caused by bacterial stimuli

\begin{tabular}{|c|c|c|c|c|c|c|}
\hline \multirow{2}{*}{$\begin{array}{l}\text { Bacterium or bacterial } \\
\text { PAMP }\end{array}$} & \multirow[t]{2}{*}{ Type of cell } & \multirow{2}{*}{$\begin{array}{l}\text { GSK3 } \beta \text { Inhibition: + pSer9 } \\
\text { GSK3 } \beta \text { Activation: } \\
\text { - pSer9 or + pTyr216 }\end{array}$} & \multirow{2}{*}{$\begin{array}{l}\text { NF-kB Inhibition } \downarrow \\
\text { NF-kB Activation } \uparrow \text { Not tested - }\end{array}$} & \multirow{2}{*}{$\begin{array}{l}\text { Pro or anti- inflammatory } \\
\text { molecules Expressed }\end{array}$} & \multirow{2}{*}{$\begin{array}{l}\text { Pro or anti-inflammatory } \\
\text { molecules Inhibited }\end{array}$} & \multirow[t]{2}{*}{ Refs. } \\
\hline & & & & & & \\
\hline LPS & Human monocytes & + pSer9 & $\downarrow$ & IL-10 & 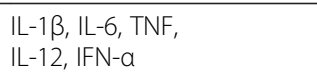 & {$[10,27$} \\
\hline LPS & Human monocytes & + pSer9 & - & IL-1Ra & $I L-1 \beta$ & [28] \\
\hline Mycobacterium bovis & Primary human monocytes & + pSer9 & - & IL-10 & $\mathrm{IFN}-\gamma$ & {$[30]$} \\
\hline Muramyl dipeptide & $\begin{array}{l}\text { Human embryonic kidney } \\
\text { epithelial cells }\end{array}$ & + pSer9 & $\downarrow$ & - & IL-8 & [31] \\
\hline LPS & Neonatal mouse cardiac cells & & $\downarrow$ & - & TNF-a & {$[36]$} \\
\hline LPS & Mice macrophages & + pSer9 & - & IFN $\beta$ & - & {$[37]$} \\
\hline Burkholderia cenocepacia & $\begin{array}{l}\text { Human monocytes and } \\
\text { mouse macrophages }\end{array}$ & + pSer9 & $\uparrow$ & TNF-a, IL-6, IL-8 & - & [38] \\
\hline $\mathrm{Pam}_{3} \mathrm{Cys}^{\mathrm{b}}$ and IFN- $\gamma$ & Human macrophages & - pSer9 & - & TNFa & $\| \mathrm{L}-10$ & [39] \\
\hline Staphylococcus aureus & Murine microglia & + pTyr216 & $\uparrow$ & TNF-a, NO & IL10 & {$[40]$} \\
\hline LPS & Murine microglia & A & $\uparrow$ & TNF-a & - & [41] \\
\hline Salmonella typhimurium & Mouse colonic epithelial cells & - pSer9; + pTyr216 & $\uparrow$ & TNF-a, IL-6 & - & [33] \\
\hline IFN- $\gamma$ and LPS & Murine macrophages & + pTyr216 & - & iNOS, NO & $\| \mathrm{L}-10$ & [42] \\
\hline IFN- $\gamma$ and LPS & $\begin{array}{l}\text { Mouse primary microglia } \\
\text { and astrocytes }\end{array}$ & A & - & $\begin{array}{l}\text { IL-6, CXCL1, IL-12p40, } \\
\text { CCL9, CCL2/MCP-1, } \\
\text { P- Selectin,CCL5 }\end{array}$ & CXCL2, MIP2 & [43] \\
\hline
\end{tabular}

GSK3 $\beta$ phosphorylation at Ser9 or Tyr216 was not analyzed.

${ }^{\mathrm{b}}$ Synthetic PAMP. 
accumulation of $\beta$-catenin following a short incubation with VacA, a process dependent on an active PI3K-Akt pathway and an inactive GSK3 $\beta$. The second effect was that prolonged incubation with VacA resulted in inactivation of Akt and activation of GSK3 3 , which then downregulated $\beta$-catenin activity. It was evident in this study that Wnt signaling, modulated by PI3K-Akt-GSK3 $\beta$ played a role in the pathogenesis of $H$. pylori infection, including the development of gastric cancer [46].

The lethal toxin (LeTx), produced by Bacillus anthracis, has been regarded as a key virulence factor in the pathogenesis of anthrax, causing immune paralysis, cell cycle arrest and cell death in host immune cells. These effects could contribute to the survival and proliferation of $B$. anthracis within the host. LeTx is a binary A:B toxin comprising protective antigen (PA) and lethal factor (LF) [47]. PA is a molecular transporter that allows receptor-mediated entry and release of LF into the cytosol. LF is a zinc metalloprotease that cleaves and inactivates the $\mathrm{N}$-terminal region of the mitogen-activated protein kinase (MAPK) kinases MEKs1-4 and 6-7, resulting in the inactivation of most of their downstream signaling substrates [47]. In non-dividing cells (human peripheral blood mononuclear cells or mouse primary peritoneal macrophages) brief exposure to LeTx induced the cleavage of MEKs by LF, generating cell cycle arrest in G0-G1 phase by rapid down-regulation of cyclin D1/ D2 and checkpoint kinase 1 [47]. LF also prevented TNF production in response to LPS. However, it was observed that recovery from the effects of LeTx can be facilitated by activating the PI3K-Akt-GSK3 $\beta$ signaling-mediated adaptive responses, indicating that modulation of this pathway can be beneficial against LeTx in cells depending on basal MEK1 activity for proliferation [47].

The inhibition of GSK3 via PI3K-Akt pathway has been identified in bacterial internalization processes in several host cells. For example, the invasion of HeLa cells by group B streptococcus (GBS) was associated with the activation of the PI3K and Akt kinases and GSK $3 \alpha / \beta$ phosphoinibition [48]. One of the two type III secretion systems (TTSSs) of Salmonella enterica serovar Typhimurium triggers bacterial internalization through activation of PI3K-Akt [49]. Among the effectors proteins translocated by this TTSS, the GTPase modulator SopE/E2 and the phosphoinositide phosphatase SigD are known to play key roles in the process [49]. Using a reverse-phase protein array technology in HeLa, it was reported the SigDdependent phosphorylation of Akt and its target GSK3 $\beta$, demonstrating the importance of phosphoinhibition of GSK3 $\beta$ during host cell signaling events through bacterial infection [50]. Recently, the participation of PI3K-AktGSK3 $\alpha / \beta$ pathway in Staphylococcus aureus internalization by endothelial cells was demonstrated. Although the role of the PI3K- Akt- dependent phosphorylation of GSK3 $\alpha / \beta$ in the internalization of this bacterium was not determined in this study, phosphorylation of GSK3 $\beta$ at Ser9 and GSK3 $\alpha$ at Ser21 was clearly associated with the invasion of S. aureus to the endothelial cells [51]. It is likely that in the internalization of GBS and Salmonella enterica by HeLa cells and $S$. aureus by endothelial cells, GSK3 functions by regulating the cytoskeletal rearrangement, as it was observed in macrophages RAW264.7 in which phosphorylation of paxillin at Ser126 and 130 was mediated by an ERK/GSK3 dual-kinase mechanism [52].

\section{Conclusions}

The experimental evidence accumulated so far indicates that GSK3 $\beta$ plays an essential role in the regulation of the inflammatory response during the interaction between pathogenic bacteria and animal cells. The opposing effects of GSK3 $\beta$ on the inflammation is dependent upon the bacterium or virulence factor (Mycobacterium bovis, Burkholderia cenocepacia, Staphylococcus aureus, Salmonella typhimurium, LPS, MDP), the type of cell (epithelial cells, monocytes, cardiomyocytes, macrophages, microglia or astrocytes and fibroblasts) and probably on the physiological state of the cell [16]. Although activated NF- $\mathrm{kB}$ induces an inflammatory response, the active or inactive state of GSK3 $\beta$ modulates the activity of NF- $\mathrm{k}$, either promoting or inhibiting an inflammatory response.

Apart from its fundamental regulatory role on the inflammatory response, GSK3 is associated with bacterial internalization $[48,50,51]$ and other processes related to the pathogenesis of the infection [46,47]. However, more studies are needed to clarify the details about the mechanisms that GSK3 employs to control the bacterial internalization, the pathogenesis of infection and the expression of genes with pro- or anti-inflammatory function.

\section{Abbreviations}

AP-1: Activator protein 1; APCs: Antigen-presenting cells; BCL3: B-cell lymphoma 3-encoded protein; CREB: CAMP-response element binding protein; ERK1/2: Extracellular-signal-regulated kinase 1/2; GSK3a/ $\beta$ : Glycogen synthase kinase-3 alpha/beta; HLA-DR: Major histocompatibility complex, MHC class II, cell surface receptor; LTA: Lipoteichoic acid; IFN- $/ / \beta$ : Interferon- $\gamma / \beta$; IL1R: Interleukin 1 receptor; IKK: IKB kinase; MAPK: Mitogen-activated protein kinase; MLK3: Mixed lineage kinase 3; mTORC1/2: The mammalian target of rapamycin complexes 1/2; MDP: muramyldipeptide; MyD88: Myeloid differentiation primary response gene 88; NF-kB: Nuclear factor-kB; NO: Nitric oxide; iNOS: inducible Nitric oxide synthase; Nod2: Nucleotide oligomerization domain 2; PAMPs: Pathogen associated molecular patterns; PDK1: 3'-phosphoinositidedependent kinase 1; PKA/C: Protein kinase A/C; PKB: Protein kinase B; PI3K IA: Class IA of phosphoinositide 3-kinases; PTEN: Phosphatase and tensin homologue; PRRs: Pattern recognition receptors; S6K: Ribosomal protein 6 kinase; STAT1-3: Signal-transducer and activator of transcription 1-3; TCF/ LEF: T-cell factor/lymphoid enhancer-binding factor; TIR: Toll/Interleukin-1 receptor; TIRAP: TIR-domain-containing adaptor protein; TLRs: Toll-like receptors; TRIF: TIR-domain-containing adapter-inducing interferon- $\beta$; TNFa: Tumor necrosis factor alpha; TNFR: Tumor necrosis factor receptor.

\section{Competing interests}

The authors declare that they have no competing interests. 


\section{Authors' contributions}

RCV and VMBA conceived of the review, designed, and wrote the manuscript. $A B P$, JJVA, MCJ and BBF contributed to critical reading and comments of the manuscript. All authors read and approved of the final manuscript.

\section{Acknowledgements and funding}

The authors thank Alejandro Huante-Mendoza and Octavio Silva-García for their valuable comments to the manuscript. Work on the corresponding author's laboratory is supported by Coordinación de la Investigación Científica of the Universidad Michoacana de San Nicolás de Hidalgo and Consejo Nacional de Ciencia y Tecnología (CONACYT-México), grant number 152518, and Programa Integral de Fortalecimiento Institucional (PIFI-2011-2012). VMB-A was a recipient of a sabbatical scholarship from CONACYT-México, file 118602. B.B.F. is a CIHR Distinguished Investigator, a Howard Hughes Medical Institute International Research Scholar, and UBC Peter Wall Distinguished Professor. RC-V is receiving a doctoral scholarship from CONACYT.

\section{Author details}

${ }^{1}$ Centro Multidisciplinario de Estudios en Biotecnología, Facultad de Medicina Veterinaria y Zootecnia, Universidad Michoacana de San Nicolás de Hidalgo, Morelia, Michoacán, Mexico. ${ }^{2}$ Michael Smith Laboratories, The University of British Columbia, Vancouver, BC V6T 1Z4, Canada. ${ }^{3}$ Centro Multidisciplinario de Estudios en Biotecnología, Facultad de Medicina Veterinaria y Zootecnia, Universidad Michoacana de San Nicolás de Hidalgo, Km. 9.5 s/n Carretera Morelia-Zinapécuaro, La Palma, Tarímbaro, C.P. 58893, Morelia, Michoacán, Mexico.

Received: 12 January 2012 Accepted: 22 May 2012

Published: 12 June 2012

\section{References}

1. Doble BW, Woodgett JR: GSK-3, tricks of the trade for a multi-tasking kinase. J Cell Sci 2003, 116:1175-1186.

2. Jope RS, Johnson GV: The glamour and gloom of glycogen synthase kinase-3. Trends Biochem Sci 2004, 29:95-102.

3. Wang $H$, Brown J, Martin M: Glycogen synthase kinase 3: a point of convergence for the host inflammatory response. Cytokine 2011, 53:130-140.

4. Beurel E, Michalek SM, Jope RS: Innate and adaptive immune responses regulated by glycogen synthase kinase-3 (GSK3). Trends Immunol 2010, 31:24-31.

5. Woodgett JR: Molecular cloning and expression of glycogen synthase kinase-3/factor A. EMBO J 1990, 9:2431-2438.

6. Hoeflich KP, Luo J, Rubie EA, Tsao MS, Jin O, Woodgett JR: Requirement for glycogen synthase kinase-3beta in cell survival and NF-kappaB activation. Nature 2000, 406:86-90.

7. Deng J, Miller SA, Wang HY, Xia W, Wen Y, Zhou BP, Li Y, Lin SY, Hung MC. Beta-catenin interacts with and inhibits NF-kappa B in human colon and breast cancer. Cancer Cell 2002, 2:323-334.

8. MacAulay K, Doble BW, Patel S, Hansoita T, Sinclair EM, Drucker DJ, Nagy A Woodgett JR: Glycogen synthase kinase 3a-specific regulation of murine hepatic glycogen metabolism. Cell Metab 2007, 6:329-337.

9. Bijur GN, Jope RS: Glycogen synthase kinase-3 $\beta$ is highly activated in nuclei and mitochondria. Neuroreport 2003, 14:2415-2419.

10. Wang H, Brown J, Gu Z, García CA, Liang R, Alard P, Beurel E, Jope RS, Greenway T, Martin M: Convergence of the mammalian target of rapamycin complex 1 - and glycogen synthase kinase 3 - $\beta$-signaling pathways regulates the innate inflammatory responses. J Immunol 2011, 186:5217-5226.

11. Liu P, Cheng H, Roberts TM, Zhao JJ: Targeting the phosphoinositide 3-kinase pathway in cancer. Nat Rev Drug Disc 2009, 8:627-644.

12. Viatour P, Merville MP, Bours V, Chariot A: Phosphorylation of NF-kappaB and IkappaB proteins. Implications in cancer and inflammation. Trends Biochem Sci 2005, 30:43-52.

13. Yamamoto M, Sato S, Hemmi H, Sanjo H, Uematsu S, Kaisho T, Hoshino K, Takeuchi O, Kobayashi M, Fujita T, Takeada K, Akira S: Essential role for TIRAP in activation of the signalling cascade shared by TLR2 and TLR4. Nature 2002, 420:324-329.

14. Ghosh S, Hayden MS: New regulators of NF-kappaB in inflammation. Nat Rev Immunol 2008, 8:837-848.
15. Demarchi F, Bertoli C, Sandy P, Schneider C: Glycogen synthase kinase-3 $\beta$ regulates NF-kB1/p105 stability. J Biol Chem 2003, 278:39583-39590.

16. Graham JR, Tullai JW, Cooper GM: GSK-3 represses growth factor-inducible genes by inhibiting NF-kappaB in quiescent cells. J Biol Chem 2010, 285:4472-4480.

17. Lawrence $T$, Fong $C$ : The resolution of inflammation: anti-inflammatory roles for NF-kappaB. Int J Biochem Cell Biol 2010, 42:519-523.

18. Kumar $\mathrm{H}$, Kawai $\mathrm{T}$, Akira S: Pathogen recognition in the innate immune response. Biochem J 2009, 420:1-16.

19. Steinke JW, Borish L: Cytokines and chemokines. J Allergy Clin Immunol 2006, 117:S441-S445.

20. Lawrence T, Gilroy DW: Chronic inflammation: a failure of resolution? Int J Exp Pathol 2007, 88:85-94.

21. Commins SP, Borish L, Steinke JW: Immunologic messenger molecules: cytokines, interferons, and chemokines. J Allergy Clin Immunol 2010, 125:S53-S72.

22. Arbibe L, Mira JP, Teusch N, Kline L, Guha M, Mackman N, Godowski PJ, Ulevitch RJ, Knaus UG: Toll-like receptor 2-mediated NF-kappa B activation requires a Rac1-dependent pathway. Nat Immuno/ 2000, 1:533-540.

23. Guha M, Mackman N: The phosphatidylinositol 3-kinase-Akt pathway limits lipopolysaccharide activation of signaling pathways and expression of inflammatory mediators in human monocytic cells. J Biol Chem 2002, 277:32124-32132.

24. Fukao T, Tanabe M, Terauchi Y, Ota T, Matsuda S, Asano T, Kadowaki T, Takeuchi T, Koyasu S: PI3K-mediated negative feedback regulation of IL-12 production in DCs. Nat Immunol 2002, 3:875-881.

25. Fukao T, Yamada T, Tanabe M, Terauchi Y, Ota T, Takayama T, Asano T, Takeuchi T, Kadowaki T, Hata Ji J, Koyasu S: Selective loss of gastrointestinal mast cells and impaired immunity in PI3K-deficient mice. Nat Immunol 2002, 3:295-304.

26. Martin M, Schifferle RE, Cuesta N, Vogel SN, Katz J, Michalek SM: Role of the phosphatidylinositol 3 kinase-Akt pathway in the regulation of IL-10 and IL-12 by Porphyromonas gingivalis lipopolysaccharide. J Immunol 2003, 171:717-725.

27. Martin M, Rehani K, Jope RS, Michalek SM: Toll-like receptor-mediated cytokine production is differentially regulated by glycogen synthase kinase 3. Nat Immunol 2005, 6:777-784.

28. Rehani K, Wang H, Garcia CA, Kinane DF, Martin M: Toll-like receptor mediated production of IL-1Ra is negatively regulated by GSK3 via the MAPK ERK1/2. J Immunol 2009, 182:547-553.

29. Molnarfi N, Gruaz L, Dayer JM, Burger D: Opposite regulation of IL-1 $\beta$ and secreted IL-1 receptor antagonist production by phosphatidylinositide 3-kinases in human monocytes activated by lipopolysaccharides or contact with T cells. J Immunol 2007, 178:446-454

30. Chan MM, Cheung BK, Li JC, Chan LL, Lau AS: A role for glycogen synthase kinase- 3 in antagonizing mycobacterial immune evasion by negatively regulating IL-10 induction. J Leukoc Bio/ 2009, 86:283-291.

31. Zhao L, Lee JY, Hwang DH: The phosphatidylinositol 3-kinase/Akt pathway negatively regulates Nod2-mediated NF-kappaB pathway. Biochem Pharmacol 2008, 75:1515-1525.

32. Gutiérrez-Venegas G, Cardoso-Jiménez P: Lipoteichoic acid promotes nuclear accumulation of $\beta$-catenin via AKT in human gingival fibroblasts. Int Immunopharmacol 2011, 11:1278-1284

33. Duan Y, Liao AP, Kuppireddi S, Ye Z, Ciancio MJ, Sun J: beta-catenin activity negatively regulates bacteria-induced inflammation. Lab Invest 2007, 87:613-624

34. Anson M, Crain-Denoyelle AM, Baud V, Chereau F, Gougelet A, Terris B, Yamagoe $S$, Colnot $S$, Viguier M, Perret $C$, Couty JP: Oncogenic $\beta$-catenin triggers an inflammatory response that determines the aggressiveness of hepatocellular carcinoma in mice. J Clin Invest 2012, 122:586-599.

35. Ha T, Hu Y, Liu L, Lu C, McMullen JR, Kelley J, Kao RL, Williams DL, Gao X, L $C:$ TLR2 ligands induce cardioprotection against ischaemia/reperfusion injury through a PI3K/Akt-dependent mechanism. Cardiovasc Res 2010, 87:694-703.

36. Shen E, Fan J, Peng T: Glycogen synthase kinase-3beta suppresses tumor necrosis factor-alpha expression in cardiomyocytes during lipopolysaccharide stimulation. J Cell Biochem 2008, 104:329-338.

37. Wang H, Garcia CA, Rehani K, Cekic C, Alard P, Kinane DF, Mitchell T, Martin M: IFN-beta production by TLR4-stimulated innate immune cells is negatively regulated by GSK3-beta. J Immunol 2008, 181:6797-6802. 
38. Cremer TJ, Shah P, Cormet-Boyaka E, Valvano MA, Butchar JP, Tridandapani S: Akt-mediated proinflammatory response of mononuclear phagocytes infected with Burkholderia cenocepacia occurs by a novel GSK3 $\beta$-dependent, IKB kinase-independent mechanism. J Immunol 2011, 187:635-643.

39. Hu X, Paik PK, Chen J, Yarilina A, Kockeritz L, Lu TT, Woodgett JR, Ivashkiv LB: IFN-gamma suppresses IL-10 production and synergizes with TLR2 by regulating GSK3 and CREB/AP-1 proteins. Immunity 2006, 24:563-574.

40. Cheng YL, Wang CY, Huang WC, Tsai CC, Chen CL, Shen CF, Chi CY, Lin CF: Staphylococcus aureus induces microglial inflammation via a glycogen synthase kinase 3\{beta\}-regulated pathway. Infect Immun 2009, 77:4002-4008.

41. Wang MJ, Huang HY, Chen WF, Chang HF, Kuo JS: Glycogen synthase kinase- $3 \beta$ inactivation inhibits tumor necrosis factor-a production in microglia by modulating nuclear factor $\mathrm{KB}$ and MLK3/JNK signaling cascades. J Neuroinflammation 2010, 7:99.

42. Lin CF, Tsai CC, Huang WC, Wang CY, Tseng HC, Wang Y, Kai Jl, Wang SW, Cheng YL: IFN-gamma synergizes with LPS to induce nitric oxide biosynthesis through glycogen synthase kinase-3-inhibited IL-10. J Cell Biochem 2008, 105:746-755.

43. Beurel $E$, Jope RS: Lipopolysaccharide-induced interleukin-6 production is controlled by glycogen synthase kinase- 3 and STAT3 in the brain. J Neuroinflammation 2009, 6:9.

44. Fujikawa A, Shirasaka D, Yamamoto S, Ota H, Yahiro K, Fukuda M, Shintani T, Wada A, Aoyama N, Hirayama T, Fukamachi H, Noda M: Mice deficient in protein tyrosine phosphatase receptor type $\mathrm{Z}$ are resistant to gastric ulcer induction by VacA of Helicobacter pylori. Nat Genet 2003, 33:375-381.

45. Voskas D, Ling LS, Woodgett JR: Does GSK-3 provide a shortcut for PI3K activation of Wnt signalling? F1000 Biol Rep 2010, 2:82.

46. Nakayama M, Hisatsune J, Yamasaki E, Isomotor H, Kurazono H, Hatakeyama M, Azuma T, Yamaoka Y, Yahiro K, Moss J, Hirayama T: Helicobacter pylori VacA-induced inhibition of GSK3 through the PI3K/Akt signaling pathway. J Biol Chem 2009, 284:1612-1619.

47. Ha SD, Ng D, Pelech SL, Kim SO: Critical role of the phosphatidylinositol 3-kinase/Akt/glycogen synthase kinase-3 signaling pathway in recovery from anthrax lethal toxin-induced cell cycle arrest and MEK cleavage in macrophages. J Biol Chem 2007, 282:36230-36239.

48. Burnham CA, Shokoples SE, Tyrrell GJ: Invasion of HeLa cells by group B Streptococcus requires the phosphoinositide-3-kinase signaling pathway and modulates phosphorylation of host cell Akt and glycogen synthase kinase-3. Microbiology 2007, 153:4240-4252.

49. Ly KT, Casanova JE: Mechanisms of Salmonella entry into host cells. Cell Microbiol 2007, 9:2103-2111.

50. Molero C, Rodríguez-Escudero I, Alemán A, Rotger R, Molina M, Cid VJ: Addressing the effects of Salmonella internalization in host cell signaling on a reverse-phase protein array. Proteomics 2009, 9:3652-3665.

51. Oviedo-Boyso J, Cortés-Vieyra R, Huante-Mendoza A, Yu HB, Valdez-Alarcón JJ, Bravo-Patiño A, Cajero-Juárez M, Finlay BB, Baizabal-Aguirre VM: The phosphoinositide-3-kinase-Akt signaling pathway is important for Staphylococcus aureus internalization by endothelial cells. Infect Immun 2011, 79:4569-4577.

52. Cai X, Li M, Vrana J, Schaller MD: Glycogen synthase kinase 3- and extracellular signal-regulated kinase-dependent phosphorylation of paxillin regulates cytoskeletal rearrangement. Mol Cell Biol 2006, 26:2857-2868.

doi:10.1186/1476-9255-9-23

Cite this article as: Cortés-Vieyra et al.: Role of glycogen synthase kinase- 3 beta in the inflammatory response caused by bacterial pathogens. Journal of Inflammation 2012 9:23.

\section{Submit your next manuscript to BioMed Central and take full advantage of:}

- Convenient online submission

- Thorough peer review

- No space constraints or color figure charges

- Immediate publication on acceptance

- Inclusion in PubMed, CAS, Scopus and Google Scholar

- Research which is freely available for redistribution

Submit your manuscript at www.biomedcentral.com/submit 